\title{
Fecal microbiota transplantation and its potential therapeutic uses in gastrointestinal disorders
}

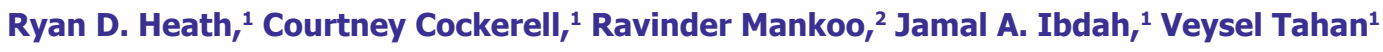 \\ ${ }^{1}$ Division of Gastroenterology and Hepatology, University of Missouri, Columbia, Missouri, USA \\ ${ }^{2}$ Department of Internal Medicine, University of Missouri-Columbia 1 Hospital Drive, Columbia, Missouri, USA
}

\begin{abstract}
Typical human gut flora has been well characterized in previous studies and has been noted to have significant differences when compared with the typical microbiome of various disease states involving the gastrointestinal tract. Such diseases include Clostridium difficile colitis, inflammatory bowel disease, functional bowel syndromes, and various states of liver disease. A growing number of studies have investigated the use of a fecal microbiota transplant as a potential therapy for these disease states.
\end{abstract}

Keywords: Disease; fecal microbiota; fecal transplantation; gastrointestinal; stool; therapy; treatment.

\section{Typical human gut microbiome}

The human gastrointestinal (GI) tract is estimated to be colonized by hundreds of bacterial species: microbiota associated with facilitating digestion, aiding in the provision of nutrition, defense against pathogens, and the development and maturation of the colonic epithelium $[1-3]$. The typical microbiota appear to vary mildly in composition for each individual; however, some generalizations have been noted. Various phyla of Firmicutes make up the majority of the microbiota in the human gut, observed to be about $40 \%$ to $70 \%$ [1-5]. These bacteria are a collective, largely composed of various Clostridium strains, Fusobaceterium strains, fecal bacterial strains, and other various genera [1-5]. Also common, though seen less frequently than the Firmicutes, are the Bacteroidetes phyla, with an estimated prevalence of approximately $25 \%$ [1-6]. It is worth noting that there does appear to be some variability of microbiota among different ethnic groups. A Tanzanian population was observed to have significantly lower Bifidobac- terium and enrichment in genera such as Prevotella and Treponema when compared with an Italian population [7]. A similar paper demonstrating microbiota variability between Western and Eastern populations reported significantly different population size and prevalence of Bacteroidetes in a Belgian population compared with Japanese [8]. Other studies have demonstrated differences between countries within the same continent, such as a 2015 study demonstrating significant variability in Bacteroidetes species in groups of Asian schoolchildren of different nationalities, and noted similar profiles between groups with comparable dietary profiles [9]. The varied response to fecal microbiota transplantation (FMT) may in part be explained by ethnic heritage and diet. Overall, however, alterations in the ratio of these groups appear to be associated with various disease states [1-3]. There is an observed "healthy" or "normal" balance between these majority phyla, changes in which are associated with pathological states in a variety of disorders including $C$. difficile colitis, inflammatory bowel disease (IBD),

Received: September 15, 2017 Accepted: November 09, 2017 Online: February 12, 2018

Correspondence: Dr. Veysel Tahan. Gastroenteroloji ve Hepatoloji Anabilim Dali, Missouri Universitesi, Columbia, Missouri, ABD.

Tel: 0014122457163 e-mail: tahanv@health.missouri.edu

(c) Copyright 2018 by Istanbul Provincial Directorate of Health - Available online at www.northclinist.com 
functional bowel disorders, and several liver diseases [1$6,10]$. Changes in the microbiome may be induced by a variety of factors. A 2015 study utilized pyrosequencing to quantify changes in the microbiota of healthy patients receiving clindamycin, ciprofloxacin, and a placebo over 12 months [2]. Overall species diversity decreased in groups receiving either antibiotic, though not in the placebo group. It warrants notice that microbiota appear to remain stable over time in healthy patients, suggesting that changes in the microbiome observed in the disease states to be discussed may be influenced by interventions undertaken by clinicians for those pathological states. A growing number of studies have been conducted utilizing FMT from a healthy human donor in the treatment of several gastrointestinal disorders, and assessing the clinical response and potential therapeutic use in those disease states.

\section{Clostridium difficile colitis}

The incidence of Clostridium difficile ( $C_{+}$difficile) infection (CDI) has been on the rise, with populations at higher risk including patients receiving chemotherapy, those with a history of solid organ transplant, and patients with IBD [11]. Beyond the rising prevalence, its marked recurrence rate necessitates consideration of alternate treatment modalities, particularly in the aforementioned higher risk populations. Studies have demonstrated that anywhere from $10 \%$ to $20 \%$ develop recurrence within 8 weeks of receiving treatment, and further recurrence in $40 \%$ to $65 \%$, suggesting that repeat episodes become more likely with each recurrence $[12,13]$. While fidaxomicin, an antibiotic with essentially no absorption from the GI tract and demonstrated to disturb the normal gut flora less than vancomycin has been utilized with success in cases of recurrent CDI, its effectiveness has been noted to decrease dramatically with further recurrences [14]. FMT is hypothesized to treat CDI by restoring normal gut flora, which compete with $C$. difficile for nutrients [15]. Multiple studies have demonstrated remarkable effectiveness of FMT in cases of recurrent CDI, perhaps due to the observed sustained restoration of the normal microbiota $[16,17]$. The loss of normal flora appears to modulate normal bile salt metabolism, which has an effect on the germination of $C$. difficile spores [18-24]. One study involving FMT and CDI utilized nasoduodenal (ND) delivery of FMT, and $81 \%$ of patients with recurrent CDI experienced resolution of symptoms, compared with $31 \%$ who received oral vancomycin [25]. Since that time, endoscopic delivery of FMT has been utilized with similar rates of success; however, a more efficient delivery of FMT has since been explored [26, 27]. Oral capsules have been formulated that demonstrate a similar efficacy. One study assessing capsules used in 20 patients with recurrent CDI observed that $70 \%$ of the patients experienced resolution of symptoms, and another 4 patients (20\%) experienced resolution after a second round of treatment [28]. A significant number of studies over time have demonstrated the reproducibility of these studies, with a 2015 meta-analysis noting 34 case studies of FMT demonstrated $90 \%$ to $97.8 \%$ resolution of diarrhea after treatment [29] (Table 1). A total of 21 of the 34 studies performed follow-up to evaluate relapse of disease and it was determined that $80.9 \%$ demonstrated no recurrence of symptoms, though the range of $46 \%$ to $100 \%$ demonstrates some variability in findings, likely attributable to variations in the mode of delivery and patient characteristics, such as age and severity of disease at presentation. Given that professional society guidelines already indicate FMT is an option in patients with refractory CDI, further studies are needed to assess the relative safety and cost effectiveness of each FMT mode of delivery to determine the optimum medium of administration and to potentially avoid the necessity of surgical intervention and improve mortality rates $[30,31]$.

TABLE 1. Summary of studies involving fecal microbiota transplantation and Clostridium difficile colitis

\begin{tabular}{lcccc} 
Author, year & Method & Mode of FMT Delivery & $\mathrm{n}$ & Outcome \\
\hline Van Nood et al., 2013 [25] & RCT & Nasoduodenal tube & 43 & $81 \%$ resolution of symptoms \\
Cammarota et al., 2015 [26] & RCT & Colonoscopy & 20 & $90 \%$ resolution \\
Kelly et al., 2016 [27] & RCT & Colonoscopy & 46 & $90.9 \%$ resolution \\
Youngster et al., 2014 [28] & RCT & Oral capsule & 20 & $70 \%$ resolution of symptoms \\
Rossen et al., 2015 [29] & Meta-analysis & Various & 1029 & $90-97.8 \%$ resolution \\
\hline
\end{tabular}

FMT: Fecal microbiota transplantation; RCT: Randomized controlled trial. 


\section{Inflammatory bowel disease}

Studies have demonstrated evidence of dysbiosis in both Crohn's disease (CD) and ulcerative colitis (UC), particularly with a noted decrease of Bacteroidetes and Firmicutes in association with relative increases in Proteobacteria, Campylobacter, Escherichia coli, Mycobacterium, and Actinobaceria [32-35]. Another observation study reported that individuals with an NOD2 gene mutation, predisposing individuals to developing IBD, have a similar dysbiosis [36]. In 1989, UC patients with symptoms refractory to steroid and sulfasalazine therapy were administered FMT enemas with a resultant improvement in active inflammation and symptoms, though chronic inflammation remained on mucosal biopsy [37]. Subsequent studies of patients with IBD refractory to 5-aminosalicylic acid, steroids, and azathioprine demonstrated similar results with clinical remission ranging from 3 months to 13 years $[38,39]$. One 2014 meta-analysis of 122 patients across multiple observation studies noted a potential disparate impact of FMT in different types of IBD, with pooled results from 18 studies demonstrating clinical remission of $36.2 \%$ in UC patients versus $60.5 \%$ in CD patients [40]. Another 2015 meta-analysis, however, found a significantly greater response in UC patients versus CD patients [29]. The variability in response to FMT in UC patients was wide, however, ranging from $0 \%$ to $68 \%$. Furthermore, it appears that only 6 patients with CD were included in this meta-analysis, suggesting insufficient evidence in this particular analysis to comment on the response to FMT in CD patients. More recent studies demonstrate similarly mixed results, with a generally more positive outlook regarding FMT in IBD. One 2015 randomized control trial (RCT), the first published regarding FMT and IBD involving UC patients, demonstrated that 9 of 38 patients (24\%) experienced clinical remission with the use of an FMT enema, compared with 2 of 37 who were given a water enema placebo. A positive outcome was defined as a Mayo score of less than 3 and an endoscopic Mayo score of 0 at 7 weeks following 6 once weekly enemas [41]. Some interesting observations among the group of FMT recipients with positive outcomes were noted. The first was an inverse association between disease length and positive outcome, with 3 out of the 4 patients in the experimental arm who had the disease for only 1 year entering into clinical remission. In addition, greater microbiota diversity was observed in the FMT group compared with the control group. Also of interest, the microbiota of patients in the experimental group with a positive outcome had shifted toward greater similarity to that of the donor stool. Another RCT published in 2015 utilized 2 ND infusions of FMT 3 weeks apart versus autologous stool infusion in 48 UC patients with mild to moderately active disease and no significant difference between the groups was found when assessing clinical remission over a 12 -week period [42]. Consistency with the aforementioned 2015 study is observed, however, as the microbiota of the responders did shift to more closely resemble donor microbiota in that arm of the trial. A third RCT, the Faecal Microbiota Transplantation in Ulcerative Colitis (FOCUS) trial, included 85 UC patients with active UC and assessed clinical and endoscopic remission in a comparison of FMT by colonoscopy followed by FMT enema 5 days per week for a total of 8 weeks and a placebo. A remission rate of $27 \%(11 / 41)$ was observed in the FMT group versus $8 \%$ remission in the placebo group [43]. Patients from the control group later received the FMT regimen as an extension of the study, and 27\% (10/37) experienced clinical remission. Of interest, each FMT was prepared with stool from 3 to 7 unrelated donors. These results suggest some promise regarding the use of FMT for the treatment of IBD, although further research assessing various delivery modalities in both $\mathrm{CD}$ and UC appears warranted. The disparity of results among the aforementioned cases may be explained by the route of FMT administration in the second 2015 study, suggesting that perhaps ND infusion is an inferior method of delivery in patients with UC when compared with endoscopic delivery or enema in this population. Furthermore, as more data are gathered regarding an appropriate donor profile, studies like the second 2015 RCT may yield more positive data with a different donor source.

What is striking regarding reviewing these studies is the lack of any RCT evaluating CD, which is underrepresented in FMT literature. Recent publications, including case series and prospective cohort studies, reviewing the utility of FMT in IBD patients unresponsive to immunosuppressive therapy included $\mathrm{CD}$ and offer some promise in this regard. These studies, as well as the RCTs mentioned, are summarized in Table 2. Case reports from 2013 and 2014 detailed individual patients with refractory $\mathrm{CD}$ who underwent FMT with subsequent clinical remission [44, 45]. A 2015 prospective study assessed 9 patients with a mild to moderate Crohn's Disease Activity Index score who received FMT via nasogastric tube (NGT) and were followed for 12 weeks [46]. Seven of the 9 patients had an improved Pediatric Crohn's Disease 
TABLE 2. Summary of studies involving fecal microbiota transplantation and inflammatory bowel disease

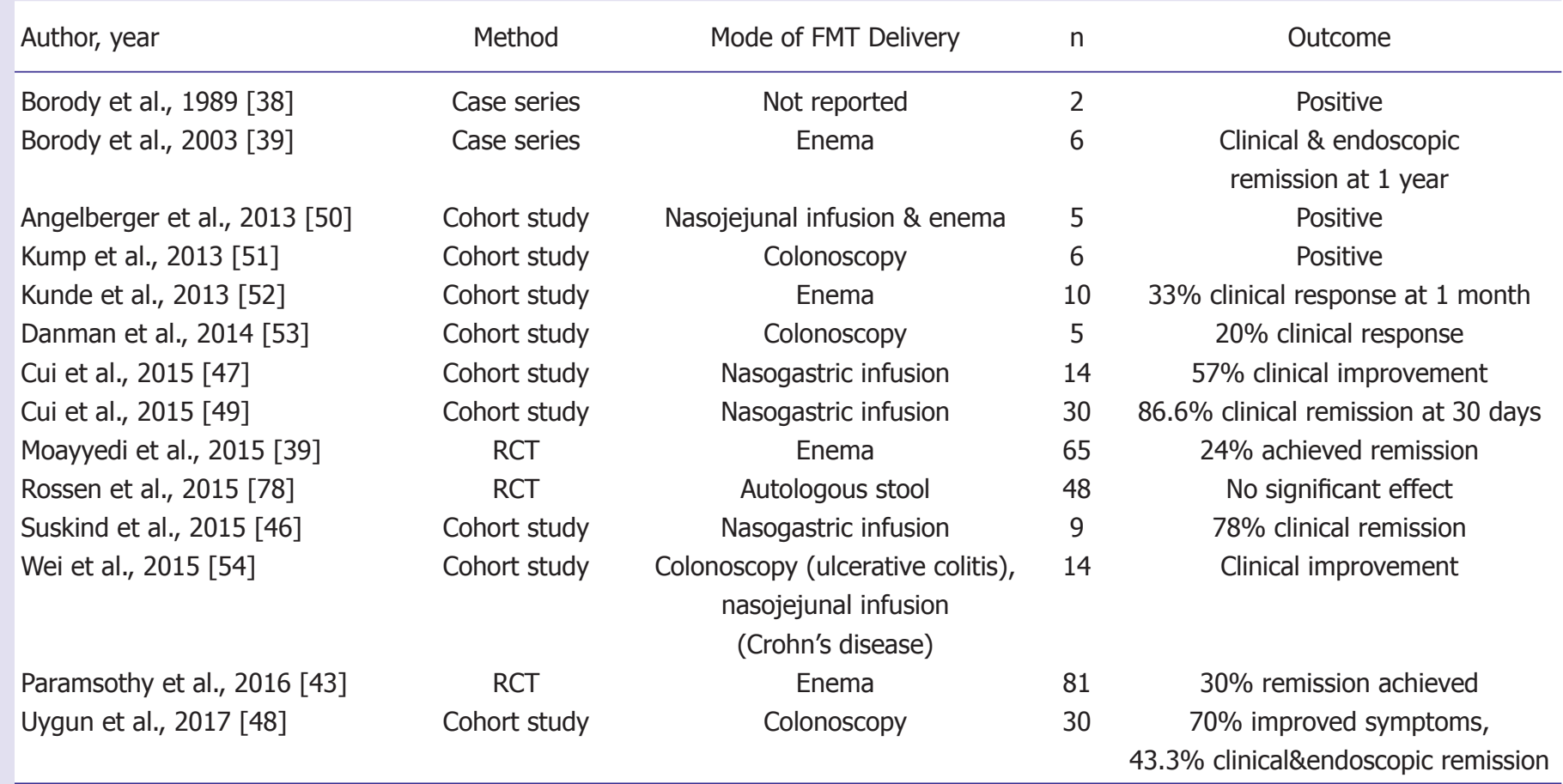

FMT: Fecal microbiota transplantation; RCT: Randomized controlled trial.

Activity score at 2 weeks, and 5 remained in remission at 12 weeks. Levels of erythrocyte sedimentation rate (ESR), C-reactive protein (CRP), and fecal calprotectin decreased over the measured 12 weeks. Another prospective, uncontrolled study followed 30 Crohn's patients with a Harvey-Bradshaw Index score of $>7$, indicating severe disease, treated with a single NGT-administered FMT [47]. Twenty-six of the 30 patients were observed to be in clinical remission 1 month after receiving FMT. Furthermore, 30 patients with refractory UC who received endoscopically delivered FMT to the proximal ileum were followed in a recent prospective, uncontrolled study. A colonoscopy was repeated 12 weeks later, and Mayo scores calculated pre and post treatment were compared. A total of 21 patients experienced improved clinical symptoms, and 13 experienced clinical and endoscopic remission [48]. In addition, a recent prospective study assessed 14 patients with steroid-dependent UC who received FMT via NGT administration. Mesalamine was continued in these patients. Eight patients demonstrated clinical improvement and at least temporarily discontinued prednisone. Five of these patients received FMT once, 1 received FMT twice, and the other 2 patients followed a prednisone dose tapering regime in addition to a second FMT. At 18 months, 4 patients had maintained clinical remission. Microbiota analysis was performed on all patients pre and post FMT. It was noted that the best response was seen among patients whose microbiota appeared to be restructured most similarly to that of the donor FMT [49]. As mentioned above, donor selection appears to be an important factor in inducing remission. Also noted was the great diversity of modes of delivery of FMT in IBD. More research in this area is needed to determine the optimal delivery modality.

\section{Functional bowel syndromes}

Functional bowel syndromes are broadly defined disorders with variably characterized abdominal pain and altered bowel frequencies; the prevalence is estimated to be about $15 \%$ [55]. The etiologies of disorders such as irritable bowel syndrome (IBS), are not completely understood, though there is evidence that alterations in gut microbiota may be at least partially responsible for the symptoms. Genomic sequencing studies in patients meeting the Rome III criteria for IBS have demonstrated significantly lower concentrations of Lactobacilli and Bifidobacteria, as well as general increases in Firmicutes, 
TABLE 3. Studies involving use of fecal microbiota transplantation and functional bowel disorders

Author

Borody et al., 1989 [38]

Andrews et al., 1995 [63]

Hoyeda et al., 2009 [62]

Ford et al., 2009 [64]

Tian et al., 2016 [65]
Method

Prospective cohort study

Prospective cohort study

Meta-analysis

Meta-analysis

Prospective cohort
Mode of FMT Delivery

Enema

Colonoscopy \& enema

Probiotics

Various

Nasojejunal tube $\mathrm{n}$

55

45

895

1921

24
Outcome

$36 \%$ reported improved symptoms

$89 \%$ improved symptoms Positive trend with various formulation

70\% reported improvement

Improvement in number

of bowel movements

FMT: Fecal microbiota transplantation.

Lachnospiraceae, and Enterobacteriaceae [56-61]. A 1989 prospective cohort study evaluated 55 patients receiving FMT via enema and 36\% achieved resolution of symptoms, 6 patients reported partial relief, and the remaining $60 \%$ noted no change in symptoms [38]. As the study did not attempt to exclude existing $C$. difficile infection nor patients with IBD, it is unclear to what extent FMT alleviated symptoms for patients with properly defined functional bowel disorders. A 2009 metaanalysis of 23 trials utilizing probiotics in patients with established IBS demonstrated a significant improvement in symptoms, prompting further investigation of altering gut microbiome to alleviate IBS symptoms [62]. A 1995 cohort study involving 45 patients with chronic constipation symptoms underwent FMT via colonoscopy and subsequent FMT via enema and 89\% reported relief of pain and frequency in defecation [63]. A prospective cohort study conducted the same year evaluated patients with IBS with constipation and found overall improvement in mean bowel movements per week in 24 patients who received FMT via nasojejunal tube (NJT) followed for 12 weeks [64]. A more recent 2016 prospective cohort study followed 24 patients with chronic constipation receiving FMT via NJT for up to 12 weeks and determined that there was an improvement in the mean number of stools per week from 1.8 to 4.3 [65]. A 2017 study of mice receiving FMT from IBS with diarrhea patients demonstrated faster gastrointestinal transit, intestinal barrier dysfunction, innate immune activation, and anxiety-like behavior when compared with controls, suggesting that one's microbiota may impact bowel habits, as well as suggesting a potential side effect of FMT [66]. Given these observations, FMT appears promising as a potential therapy for functional bowel disorders (Table 3).

\section{Cirrhosis, hyperammonemia, and chronic hepatitis}

Hyperammonemia and hepatic encephalopathy have long been associated with each other and with a worsening prognosis in cirrhosis. Recent evidence demonstrates FMT may be capable of replacing urease-producing bacteria in human gastrointestinal tracts with a metabolically different population and mitigating the symptoms of altered mentation. It is worth noting early that mammalian genes do not encode for urease; ammonia is a result of metabolism via bacterial urease. Ammonia is then either reabsorbed or excreted fecally [67]. In a 2014 randomized control study, FMT with low urease activity was administered to mice via a bacterial slurry [68]. Significantly reduced fecal ammonia levels were observed in the experimental group after FMT. Also, no urease activity was observed in pellets from mice colonized from the FMT group, a response that was sustained for at least 80 days.

Fecal ammonia levels were lower in FMT mice than in control mice treated with a low protein diet alone. After documentation of the above measurements and completion of this arm of the study, hepatic injury was then induced in the same groups using thioacetamide (TAA). The mice that had undergone FMT had lower fecal ammonia levels as well as reduced mortality after infusion of TAA. To assess dose response, lower concentrations of TAA were also introduced in progressively increasing doses over 7 weeks at a point 3 weeks from initial FMT. The mice in the FMT group were observed to have a lower mortality rate during this period, though fibrosis was observed in both arms, suggesting a potential hepatoprotective effect of FMT. A 2015 case report reinforced this conclusion [69]. This case report described a 57-year-old male with cirrhosis secondary to both al- 
cohol and the hepatitis $\mathrm{C}$ (HCV) virus, decompensated by grade 2 portal systemic encephalopathy. The patient had previously responded to a regimen of lactulose and rifaximin, however, for financial reasons was unable to continue the rifaximin. Consequently, his clinical course declined. Via a universal stool donor, this patient underwent FMT with a reduction observed in serum ammonia levels as well as improved cognition. Analysis of his stool microbial diversity demonstrated shifts in his own microbiota toward that of the donor. This composition shift correlated with improvement in his encephalopathy. Regrettably, 10 weeks after his final FMT, his cognitive status declined to the previously observed encephalopathy. Repeat analysis of his microbiota was not performed at this point. While a suspected shift back toward his original composition was not documented, this case suggests an opportunity for research with a larger number of participants and more frequent observation of shifts in microbial diversity related to FMT over time, and particularly changing the physical exam.

In this regard, recent hepatitis B (HBV) research suggests an opportunity for the use of FMT to clear viral hepatitis and consequently avoid later complications such as encephalopathy. Mice aged 6 to 12 weeks and inoculated with HBV did not clear the virus in the youngest group after administration of antibiotics intended to sterilize the GI tract [70]. Mice of equivalent age with mutations rendering them unable to respond to these same antibiotics, however, cleared the virus rapidly. A 2015 prospective cohort trial analyzed 5 patients with chronic $\mathrm{HBV}$ and the serum hepatitis $B$ virus e antigen $(\mathrm{HBeAg})$ who received endoscopically administered FMT for a period of up to 7 weeks [71]. The recipients' microbiota were analyzed after each treatment and became increasingly similar to that of the donor. A reduction in $\mathrm{HBeAg}$ titers was noted after each treatment. Two patients achieved clearance after 1 treatment, another achieved clearance after a second treatment. A fifth patient left the trial after the first 4 treatments. Thirteen control patients were included, none of whom demonstrated any change in microbiota composition or reduction of serum $\mathrm{HBeAg}$. Therefore, FMT may function as a potential immunomodulator and may perhaps be used to treat chronic HBV. Further trials are needed to evaluate the potential role of FMT for etiologies of viral hepatitis.

\section{Primary sclerosing cholangitis}

FMT also may be useful for treating primary sclerosing cholangitis (PSC). Chronic cholangitis has been hypoth- esized to develop secondary to endotoxin production or secondary to microbial metabolites, progressing in time to clinically evident PSC [72-74]. Consequently, altered microbial diversity or metabolism is hypothesized to produce a pathological cholangiocyte response, resulting in inflammation or apoptosis, and perhaps affecting the cell's ability to respond appropriately to injury over time $[4,6,74]$. Metabolites, such as lipopolysaccharide, lipoteichoic acid, and various DNA fragments of bacterial organisms have been observed in the bile, cholangiocytes, and portal tracts of patients with cholestatic liver disease $[4,5,72]$. Evaluation of the relative microbiome diversity of patients with PSC, PSC and concomitant IBD, as well as healthy control patients yielded generally complementary results, demonstrating significantly reduced Clostridium strains in patients with PSC $[75,76]$. Also observed in patients with PSC who lacked markers for IBD was an overall decreased diversity of microbiota and an increased presence of Lactobacillus, Enterococcus, and Fusobacterium compared with controls [77-78].

Given this information regarding an altered microbiome in PSC patients, FMT may have a therapeutic role in this disease state. Two publications lay additional groundwork for such a hypothesis. One prospective study documented improved alkaline phosphatase (ALP) levels in PSC patients treated with a low dose of vancomycin, thought to be secondary to subsequent alterations in these patients' microbiota [74]. There is also a case report of 1 PSC patient who had previously undergone liver transplantation who had an improvement in ALP after administration of vancomycin [80]. While this is a small group of patients from which to draw conclusions, FMT appears to be an alternative means to achieve a shift in fecal microbiota. It has previously been hypothesized that probiotics may be able to play a similar role in PSC, though a variety of studies suggest no consistent and clear consequence of their use, likely secondary to a variety of treatment durations and varying compositions of probiotics [81]. FMT may more easily and directly affect microbiota than probiotics in PSC. A recent clinical trial at Brigham and Women's Hospital in the USA evaluated the impact of FMT in PSC patients. The study's primary outcome measures include genotyping and a comparison of recipient microbiota before and after FMT in addition comparison with the donor's microbiota. Liver chemistry was measured over 3 months, with success defined as a $50 \%$ reduction in the levels of ALP, alanine transaminase, aspartate aminotransferase, and total bilirubin. This study concluded in April 2017 [82]. 
Safety considerations in fecal transplantation and thoughts on future application

The aforementioned meta-analyses, especially regarding $\mathrm{CDI}$ and IBD, do note infrequent cases of flares requiring hospitalization and, in 1 case, colectomy [83, 84]. Given the altered microbiota in various disease states, it is worth noting that FMT donor stool is tested for multiple infectious diseases, including HIV and HCV, as well as screened for recent use of antibiotics, immunosuppressant medication, or the presence of metabolic or malignant disease $[29,83]$. In the future, the sequencing of donor stool before transplantation may be considered, as further data are collected demonstrating the "typical" microbiota of previously successful FMTs.

A legitimate concern cited by many authors has been inducing systemic infection with the introduction of a foreign microbiome into the GI tract of patients, and particularly immunosuppressed patients [29, 8387]. Based on the previously discussed studies utilizing FMT in patients taking immunosuppressive drugs, such as IBD patients, a potential future use of FMT involves graft versus host disease (GVHD) of the lower GI tract. Given the previously noted dysbiosis associated with GVHD with lower GI tract involvement, 1 observation study of the use of FMT in such cases noted 2 trials of FMT in refractory CDI patients with a history of solid organ transplant who experienced no post-transplantation-related infection, though cases of aspiration were noted $[88,89]$. In this study, 3 patients with GI-involved GVHD and dysbiosis demonstrated by fecal genotyping received endoscopic FMT on a weekly basis, and 2 patients demonstrated reconstituted microbiota and improved symptoms at 8 and 9 weeks [85]. The third patient did not achieve remission, though this patient's microbiota did appear to be briefly reconstituted and there was improvement in diarrhea before relapse. A separate 2016 case series involving 4 patients with steroid-refractory or steroid-dependent gut-involved GVHD also observed clinical remission in 3 of the 4 cases after use of FMT [89]. Cumulatively, while only 7 patients have been reported on, this is yet another disease that appears to be amenable to FMT.

A review of the data regarding FMT suggests that earlier application of FMT may potentially lead to more successful interventions. For instance, the aforementioned GVHD cases were all steroid-dependent or refractory cases. Studies involving GVHD at the time of diagnosis may provide more insight on the ability of
FMT to be a successful intervention. Similarly, as discussed earlier, patients with a more recent IBD diagnosis who underwent treatment with FMT appeared to generally have a relatively greater chance of a positive outcome. Regarding the safety profile, known adverse effects of FMT are cramping and nausea $[29,83,84]$. In terms of serious adverse effects, there have been instances of IBD flares reported in patients with IBD and CDI treated with FMT. While these studies document overall improvement in patients' clinical status following FMT, a minority of patients has experienced this complication. One 2014 retrospective uncontrolled study utilizing endoscopically delivered FMT resulted in an overall cure rate of $89 \%$; however, 5 patients experienced disease flare [88]. Another 2016 cohort study followed 67 IBD patients with CDI, and 2 experienced IBD flare after FMT [90]. One 2016 case report documented what appears to be the first case of flare of extra-intestinal CD manifestations after endoscopically delivered FMT for CDI [91]. It is unclear why IBD patients may be at risk for flares after FMT, although a 2014 case report demonstrated documented bacteremia after FMT, leading to the hypothesis that transient bacteremia may result in altered intestinal permeability resulting in a flare [92]. One 2013 case report documented the case of a UC patient in clinical remission for 20 years who developed a flare of the disease after successful treatment of CDI with FMT [93]. Development of diffuse arthralgia with photographed erythema nodosum, as well as a concurrent increase in ESR and CRP levels, was successfully treated with prednisone.

A great deal of heterogeneity is seen regarding the delivery modality of FMT. Given that oral medications are cheaper than endoscopic intervention, it appears sensible that treatment utilizing this mode of delivery has historically been the initial approach. As we have demonstrated in this review, there are oral formulations of FMT which can be used safely in conjunction with the classic firstline treatments for the previously discussed disorders, and possibly augment the effectiveness of those treatments. Furthermore, a direct comparison of the different modes of delivery of FMT has not been performed in a single clinical trial. While oral formulations may be cheaper, it may ultimately be more cost effective to utilize nasoenteral or endoscopically delivered FMT should the initial response to these relatively higher risk modalities be sufficiently greater. Nasoenteric administration is minimally invasive; however, it comes with an increased risk of aspiration and emesis. Endoscopic administration 
has the advantages of direct visualization of the GI tract; however, there are the standard risks of sedation and procedural intervention, in addition to the higher cost of performing the procedure. Oral capsules prepared from stool are the least invasive; however, less evidence is available regarding effectiveness. Previously, fresh stool was thought to be necessary for successful transfer, but recent studies demonstrate no loss of efficacy using capsules prepared from frozen stool when compared with those prepared with fresh stool $[25,94,95]$. The relative safety profile of fresh versus frozen FMT oral capsules has not been thoroughly characterized.

In any case, standardization of FMT practices will certainly be necessary. As such, the American Gastroenterology Association is creating a national FMT registry, a consortium of case reports and studies with the goals of serving as an efficient and comprehensive database of current research on FMT and providing the ability to discuss areas in which further research is warranted [96]. Ultimately, further investigation regarding the effectiveness and appropriate timing of FMT for the disorders discussed appears not only justified, but promising, as well.

Conflict of Interest: No conflict of interest was declared by the authors.

Financial Disclosure: The authors declared that this study has received no financial support.

Authorship contributions: Concept - R.D.H., C.C., R.M., J.A.I., V.T.; Design - R.D.H., C.C., R.M., J.A.I., V.T.; Supervision - R.D.H., C.C., R.M., J.A.I., V.T.; Materials - R.D.H., C.C., R.M., J.A.I., V.T.; Data collection \&/or processing - R.D.H., C.C., R.M., J.A.I., V.T.; Analysis and/or interpretation - R.D.H., C.C., R.M., J.A.I., V.T.; Writing R.D.H., C.C., R.M., J.A.I., V.T.; Critical review - R.D.H., C.C., R.M., J.A.I., V.T.

\section{REFERENCES}

1. Duncan SH, Louis P, Flint HJ. Cultivable bacterial diversity from the human colon. Lett Appl Microbiol 2007;44:343-50. [CrossRef]

2. Rashid MU, Zaura E, Buijs MJ, Keijser BJ, Crielaard W, Nord CE, et al. Determining the Long-term Effect of Antibiotic Administration on the Human Normal Intestinal Microbiota Using Culture and Pyrosequencing Methods. Clin Infect Dis 2015;60:S77-84. [CrossRef]

3. Chang JY, Antonopoulos DA, Kalra A, Tonelli A, Khalife WT, Schmidt TM, et al. Decreased diversity of the fecal Microbiome in recurrent Clostridium difficile-associated diarrhea. J Infect Dis 2008;197:435-8.

4. Abdul-Hai A, Abdallah A, Malnick SD. Influence of gut bacteria on development and progression of non-alcoholic fatty liver disease. World J Hepatol 2015;7:1679-84. [CrossRef]

5. Jasmohan S Bajaj, Douglas M Heuman, Phillip B Hylemon, Arun J Sanyal, Melanie B White, Pamela Monteith, et al. The Cirrhosis Dysbiosis Ratio defines Changes in the Gut Microbiome Associated with Cirrhosis and its Complications. J Hepatol 2014;60:940-947. [CrossRef]

6. Qin N, Yang F, Li A, Prifti E, Chen Y, Shao L. Alterations of the human gut microbiome in liver cirrhosis. Nature 2014;513:59-64. [CrossRef]

7. Schnorr SL, Candela M, Rampelli S, Centanni M, Consolandi C, Basaglia G, et al. Gut microbiome of the Hadza hunter-gatherers. Nat Commun 2014;5:3654. [CrossRef]

8. Ishikawa E, Matsuki T, Kubota H, Makino H, Sakai T, Oishi K, et al. Ethnic diversity of gut microbiota: species characterization of Bacteroides fragilis group and genus Bifidobacterium in healthy Belgian adults, and comparison with data from Japanese subjects. J Biosci Bioeng 2013;116:265-70. [CrossRef]

9. Nakayama J, Watanabe K, Jiang J, Matsuda K, Chao SH, Haryono P, et al. Diversity in gut bacterial community of school-age children in Asia. Sci Rep 2015;5:8397. [CrossRef]

10. Bäckhed F. Programming of host metabolism by the gut microbiota. Ann Nutr Metab 2011;58:44-52. [CrossRef]

11. Khanna S, Pardi DS. The growing incidence and severity of Clostridium difficile infection in inpatient and outpatient settings. Expert Rev Gastroenterol Hepatol 2010;4:409-16. [CrossRef]

12. McFarland LV, Surawicz CM, Rubin M, Fekety R, Elmer GW, Greenberg RN. Recurrent Clostridium difficile disease: epidemiology and clinical characteristics. Infect Control Hosp Epidemiol 1999;20:43-50

13. Bouza E. Consequences of Clostridium difficile infection: understanding the healthcare burden. Clin Microbiol Infect 2012;18:5-12. [CrossRef]

14. Bagdasarian N, Rao K, Malani PN. Diagnosis and treatment of Clostridium difficile in adults: a systematic review. JAMA 2015;313:398-408.

15. Choi HH, Cho YS. Fecal Microbiota Transplantation: Current Applications, Effectiveness, and Future Perspectives. Clin Endosc 2016;49:257-65. [CrossRef]

16. Khoruts A, Dicksved J, Jansson JK, Sadowsky MJ. Changes in the composition of the human fecal microbiome after bacteriotherapy for recurrent Clostridium difficile-associated diarrhea. J Clin Gastroenterol 2010;44:354-60.

17. Hamilton MJ, Weingarden AR, Sadowsky MJ, Khoruts A. Standardized frozen preparation for transplantation of fecal microbiota for recurrent Clostridium difficile infection. Am J Gastroenterol 2012;107:761-7.

18. Stellwag EJ, Hylemon PB. Characterization of 7-alpha-dehydroxylase in Clostridium leptum. Am J Clin Nutr 1978;31:S243-S247. [CrossRef]

19. Hirano S, Nakama R, Tamaki M, Masuda N, Oda H. Isolation and characterization of thirteen intestinal microorganisms capable of $7 \mathrm{al}$ pha-dehydroxylating bile acids. Appl Environ Microbiol 1981;41:73745.

20. Takamine F, Imamura T. Isolation and characterization of bile acid 7-dehydroxylating bacteria from human feces. Microbiol Immunol 1995;39:11-8. [CrossRef]

21. Doerner KC, Takamine F, LaVoie CP, Mallonee DH, Hylemon PB. Assessment of fecal bacteria with bile acid 7 alpha-dehydroxylating activity for the presence of bai-like genes. Appl Environ Microbiol 1997;63:1185-8.

22. Kitahara M, Takamine F, Imamura T, Benno Y. Assignment of Eubacterium sp. VPI 12708 and related strains with high bile acid 7alphadehydroxylating activity to Clostridium scindens and proposal of Clostridium hylemonae sp. nov., isolated from human faeces. Int J Syst Evol Microbiol 2000;50:971-8. [CrossRef]

23. Ridlon JM, Kang DJ, Hylemon PB. Bile salt biotransformations by human intestinal bacteria. J Lipid Res 2006;47:241-59. [CrossRef]

24. Sorg JA, Sonenshein AL. Bile salts and glycine as cogerminants for Clostridium difficile spores. J Bacteriol 2008;190:2505-12. [CrossRef]

25. van Nood E, Vrieze A, Nieuwdorp M, Fuentes S, Zoetendal EG, de Vos WM, et al. Duodenal infusion of donor feces for recurrent Clostridium difficile. N Engl J Med 2013;368:407-15. [CrossRef]

26. Cammarota G, Masucci L, Ianiro G, Bibbò S, Dinoi G, Costamagna $\mathrm{G}$, et al. Randomised clinical trial: faecal microbiota transplantation by 
colonoscopy vs. vancomycin for the treatment of recurrent Clostridium difficile infection. Aliment Pharmacol Ther 2015;41:835-43. [CrossRef]

27. Kelly CR, Khoruts A, Staley C, Sadowsky MJ, Abd M, Alani M, et al. Effect of Fecal Microbiota Transplantation on Recurrence in Multiply Recurrent Clostridium difficile Infection: A Randomized Trial. Ann Intern Med 2016;165:609-616. [CrossRef]

28. Youngster I, Sauk J, Pindar C, Wilson RG, Kaplan JL, Smith MB, et al. Fecal microbiota transplant for relapsing Clostridium difficile infection using a frozen inoculum from unrelated donors: a randomized, open-label, controlled pilot study. Clin Infect Dis 2014;58:1515-22. [CrossRef]

29. Rossen NG, MacDonald JK, de Vries EM, D'Haens GR, de Vos WM, Zoetendal EG, et al. Fecal microbiota transplantation as novel therapy in gastroenterology: A systematic review. World J Gastroenterol 2015;21:5359-71. [CrossRef]

30. Surawicz CM, Brandt LJ, Binion DG, Ananthakrishnan AN, Curry SR, Gilligan PH, et al. Guidelines for diagnosis, treatment, and prevention of Clostridium difficile infections. Am J Gastroenterol 2013;108:478-98.

31. Debast SB, Bauer MP, Kuijper EJ; European Society of Clinical Microbiology and Infectious Diseases. European Society of Clinical Microbiology and Infectious Diseases: update of the treatment guidance document for Clostridium difficile infection. Clin Microbiol Infect 2014;20:1-26. [CrossRef]

32. Ott SJ, Musfeldt M, Wenderoth DF, Hampe J, Brant O, Fölsch UR. Reduction in diversity of the colonic mucosa associated bacterial microflora in patients with active inflammatory bowel disease. Gut 2004;53:685-93. [CrossRef]

33. Frank DN, St Amand AL, Feldman RA, Boedeker EC, Harpaz N, Pace NR. Molecular-phylogenetic characterization of microbial community imbalances in human inflammatory bowel diseases. Proc Natl Acad Sci USA 2007;104:13780-5. [CrossRef]

34. Sartor RB. Microbial influences in inflammatory bowel diseases. Gastroenterology 2008;134:577-94. [CrossRef]

35. Chassaing B, Darfeuille-Michaud A. The commensal microbiota and enteropathogens in the pathogenesis of inflammatory bowel diseases. Gastroenterology 2011;140:1720-28. [CrossRef]

36. Verdu EF, Galipeau HJ, Jabri B. Novel players in coeliac disease pathogenesis: role of the gut microbiota. Nat Rev Gastroenterol Hepatol 2015;12:497-506. [CrossRef]

37. Damman CJ, Miller SI, Surawicz CM, Zisman TL. The microbiome and inflammatory bowel disease: is there a therapeutic role for fecal microbiota transplantation? Am J Gastroenterol 2012;107:1452-9. [CrossRef]

38. Borody TJ, George L, Andrews P, Brandl S, Noonan S, Cole P, et al. Bowel-flora alteration: a potential cure for inflammatory bowel disease and irritable bowel syndrome? Med J Aust 1989;150:604.

39. Borody TJ, Warren EF, Leis S, Surace R, Ashman O. Treatment of ulcerative colitis using fecal bacteriotherapy. J Clin Gastroenterol 2003;37:42-7. [CrossRef]

40. Colman RJ, Rubin DT. Fecal microbiota transplantation as therapy for inflammatory bowel disease: a systematic review and meta-analysis. J Crohns Colitis 2014;8:1569-81. [CrossRef]

41. Moayyedi P, Surette MG, Kim PT, Libertucci J, Wolfe M, Onischi C, et al. Fecal Microbiota Transplantation Induces Remission in Patients With Active Ulcerative Colitis in a Randomized Controlled Trial. Gastroenterology 2015;149:102-109.e6. [CrossRef]

42. Rossen NG, Fuentes S, van der Spek MJ, Tijssen JG, Hartman JH, Duflou A, et al. Findings From a Randomized Controlled Trial of Fecal Transplantation for Patients With Ulcerative Colitis. Gastroenterology 2015;149:110-118.e4. [CrossRef]

43. S. Paramsothy, M. Kamm, A. Walsh, J. van den Bogaerde, D. Samuel, R. Leong, et al. OP017 Multi-donor intense faecal microbiota transplantation is an effective treatment for resistant ulcerative colitis: a randomised placebo-controlled trial. Gastroenterology. 2016; 150:S122-S123.
44. Zhang FM, Wang HG, Wang M, Cui BT, Fan ZN, Ji GZ. Fecal microbiota transplantation for severe enterocolonic fistulizing Crohn's disease. World J Gastroenterol 2013;19:7213-6. [CrossRef]

45. Kao D, Hotte N, Gillevet P, Madsen K. Fecal microbiota transplantation inducing remission in Crohn's colitis and the associated changes in fecal microbial profile. J Clin Gastroenterol 2014;48:625-8. [CrossRef]

46. Suskind DL, Brittnacher MJ, Wahbeh G, Shaffer ML, Hayden HS, Qin X, et al. Fecal microbial transplant effect on clinical outcomes and fecal microbiome in active Crohn's disease. Inflamm Bowel Dis 2015;21:556-63. [CrossRef]

47. Cui B, Feng Q, Wang H, Wang M, Peng Z, Li P, et al. Fecal microbiota transplantation through mid-gut for refractory Crohn's disease: safety, feasibility, and efficacy trial results. J Gastroenterol Hepatol 2015;30:51-8. [CrossRef]

48. Uygun A, Ozturk K, Demirci H, Oger C, Avci IY, Turker T, et al. Fecal microbiota transplantation is a rescue treatment modality for refractory ulcerative colitis. Medicine (Baltimore) 2017;96:e6479. [CrossRef]

49. Cui B, Li P, Xu L, Zhao Y, Wang H, Peng Z, et al. Step-up fecal microbiota transplantation strategy: a pilot study for steroid-dependent ulcerative colitis. J Transl Med 2015;13:298. [CrossRef]

50. Angelberger S, Reinisch W, Makristathis A, Lichtenberger C, Dejaco $\mathrm{C}$, Papay $\mathrm{P}$, et al. Temporal bacterial community dynamics vary among ulcerative colitis patients after fecal microbiota transplantation. Am J Gastroenterol 2013;108:1620-30. [CrossRef]

51. Kump PK, Gröchenig HP, Lackner S, Trajanoski S, Reicht G, Hoffmann KM, et al. Alteration of intestinal dysbiosis by fecal microbiota transplantation does not induce remission in patients with chronic active ulcerative colitis. Inflamm Bowel Dis 2013;19:2155-65. [CrossRef]

52. Kunde S, Pham A, Bonczyk S, Crumb T, Duba M, Conrad H Jr, et al. Safety, tolerability, and clinical response after fecal transplantation in children and young adults with ulcerative colitis. J Pediatr Gastroenterol Nutr 2013;56:597-601. [CrossRef]

53. Christopher Damman, Mitchell Brittnacher, Hillary Hayden, Matthew Radey, Kyle Hager, Samuel Miller, et al. Su1403 Single Colonoscopically Administered Fecal Microbiota Transplant for Ulcerative Colitis-A Pilot Study to Determine Therapeutic Benefit and Graft Stability. Gastroenterology 2014;146:S460. [CrossRef]

54. Wei Y, Zhu W, Gong J, Guo D, Gu L, Li N, et al. Fecal Microbiota Transplantation Improves the Quality of Life in Patients with Inflammatory Bowel Disease. Gastroenterol Res Pract 2015;2015:517597.

55. Lovell RM, Ford AC. Global prevalence of and risk factors for irritable bowel syndrome: a meta-analysis. Clin Gastroenterol Hepatol 2012;10:712-721.e4. [CrossRef]

56. Distrutti E, Monaldi L, Ricci P, Fiorucci S. Gut microbiota role in irritable bowel syndrome: New therapeutic strategies. World J Gastroenterol 2016;22:2219-41. [CrossRef]

57. Kassinen A, Krogius-Kurikka L, Mäkivuokko H, Rinttilä T, Paulin L, Corander J, et al. The fecal microbiota of irritable bowel syndrome patients differs significantly from that of healthy subjects. Gastroenterology 2007;133:24-33. [CrossRef]

58. Vandeputte D, Falony G, Vieira-Silva S, Tito RY, Joossens M, Raes J. Stool consistency is strongly associated with gut microbiota richness and composition, enterotypes and bacterial growth rates. Gut 2016;65:57-62. [CrossRef]

59. Zhu L, Liu W, Alkhouri R, Baker RD, Bard JE, Quigley EM, et al. Structural changes in the gut microbiome of constipated patients. Physiol Genomics 2014;46:679-86. [CrossRef]

60. Simrén M, Barbara G, Flint HJ, Spiegel BM, Spiller RC, Vanner S, et al. Intestinal microbiota in functional bowel disorders: a Rome foundation report. Gut 2013;62:159-76. [CrossRef]

61. Mättö J, Maunuksela L, Kajander K, Palva A, Korpela R, Kassinen A, et al. Composition and temporal stability of gastrointestinal microbiota 
in irritable bowel syndrome- a longitudinal study in IBS and control subjects. FEMS Immunol Med Microbiol 2005;43:213-22. [CrossRef]

62. Hoveyda N, Heneghan C, Mahtani KR, Perera R, Roberts N, Glasziou P. A systematic review and meta-analysis: probiotics in the treatment of irritable bowel syndrome. BMC Gastroenterol 2009;9:15. [CrossRef]

63. Andrews P, Borody TJ, Shortis NP, Thompson S. Bacteriotherapy for chronic constipation-long term follow-up. Gastroenterology. 1995;108:A563 [CrossRef]

64. Ford AC, Spiegel BM, Talley NJ, Moayyedi P. Small intestinal bacterial overgrowth in irritable bowel syndrome: systematic review and metaanalysis. Clin Gastroenterol Hepatol 2009;7:1279-86. [CrossRef]

65. Tian H, Ding C, Gong J, Ge X, McFarland LV, Gu L, Wei Y, et al. Treatment of Slow Transit Constipation With Fecal Microbiota Transplantation: A Pilot Study. J Clin Gastroenterol 2016;50:865-870.

66. Pinn DM, Aroniadis OC, Brandt LJ. Is fecal microbiota transplantation the answer for irritable bowel syndrome? A single-center experience. Am J Gastroenterol 2014;109:1831-2. [CrossRef]

67. De Palma G, Lynch MD, Lu J, Dang VT, Deng Y, Jury J, et al. Transplantation of fecal microbiota from patients with irritable bowel syndrome alters gut function and behavior in recipient mice. Sci Transl Med 2017;9. [CrossRef]

68. Holecek M. Ammonia and amino acid profiles in liver cirrhosis: effects of variables leading to hepatic encephalopathy. Nutrition. 2015;31:14-20.

69. Shen TC, Albenberg L, Bittinger K, Chehoud C, Chen YY, Judge CA, et al. Engineering the gut microbiota to treat hyperammonemia. J Clin Invest 2015;125:2841-50. [CrossRef]

70. Kao D, Roach B, Park H, Hotte N, Madsen K, Bain V, at al. Fecal microbiota transplantation in the management of hepatic encephalopathy. Hepatology 2016;63:339-40. [CrossRef]

71. Chou HH, Chien WH, Wu LL, Cheng CH, Chung $\mathrm{CH}$, Horng JH, et al. Age-related immune clearance of hepatitis B virus infection requires the establishment of gut microbiota. Proc Natl Acad Sci USA. 2015;112:2175-80. [CrossRef]

72. Ren YD, Ye ZS, Yang LZ, Jin LX, Wei WJ, Deng YY, et al. Fecal microbiota transplantation induces hepatitis $\mathrm{B}$ virus e-antigen $(\mathrm{HBeAg})$ clearance in patients with positive $\mathrm{HBeAg}$ after long-term antiviral therapy. Hepatology 2017;65:1765-1768. [CrossRef]

73. Björnsson E, Cederborg A, Akvist A, Simren M, Stotzer PO, Bjarnason I. Intestinal permeability and bacterial growth of the small bowel in patients with primary sclerosing cholangitis. Scand J Gastroenterol 2005;40:1090-4. [CrossRef]

74. Mueller T, Beutler C, Picó AH, Shibolet O, Pratt DS, Pascher A, et al. Enhanced innate immune responsiveness and intolerance to intestinal endotoxins in human biliary epithelial cells contributes to chronic cholangitis. Liver Int 2011;31:1574-88. [CrossRef]

75. Tabibian JH, Weeding E, Jorgensen RA, Petz JL, Keach JC, Talwalkar JA, et al. Randomised clinical trial: vancomycin or metronidazole in patients with primary sclerosing cholangitis- a pilot study. Aliment Pharmacol Ther 2013;37:604-12. [CrossRef]

76. Torres J, Bao X, Goel A, Colombel JF, Pekow J, Jabri B, et al. The features of mucosa-associated microbiota in primary sclerosing cholangitis. Aliment Pharmacol Ther 2016;43:790-801. [CrossRef]

77. Rossen NG, Fuentes S, Boonstra K, D’Haens GR, Heilig HG, Zoetendal EG, et al. The mucosa-associated microbiota of PSC patients is characterized by low diversity and low abundance of uncultured Clostridiales II. J Crohns Colitis 2015;9:342-8. [CrossRef]

78. Sabino J, Vieira-Silva S, Machiels K, Joossens M, Falony G, Ballet V, et al. Primary sclerosing cholangitis is characterised by intestinal dysbiosis independent from IBD. Gut 2016;65:1681-9. [CrossRef]

79. Kummen M, Holm K, Anmarkrud JA, Nygård S, Vesterhus M, Høivik $\mathrm{ML}$, et al. The gut microbial profile in patients with primary sclerosing cholangitis is distinct from patients with ulcerative colitis without bil- iary disease and healthy controls. Gut 2017;66:611-619. [CrossRef]

80. J. Sabino, S. Vieira-Silva, K. Machiels, M. Joossens, G. Falony, V. Ballet, et al. DOP087 Intestinal microbial signature in patients with primary sclerosing cholangitis. J Crohns Colitis 2015;9:S72-73. [CrossRef]

81. Davies YK, Tsay CJ, Caccamo DV, Cox KM, Castillo RO, Cox KL. Successful treatment of recurrent primary sclerosing cholangitis after orthotopic liver transplantation with oral vancomycin. Case Rep Transplant 2013:314292. [CrossRef]

82. Tabibian JH, O'Hara SP, Lindor KD. Primary sclerosing cholangitis and the microbiota: current knowledge and perspectives on etiopathogenesis and emerging therapies. Scand J Gastroenterol 2014;49:901-8.

83. Korzenik J. Fecal Microbiota Transplantation for the Treatment of Primary Sclerosing Cholangitis. Available at: https://clinicaltrials.gov/ ct2/show/NCT02424175. Accessed Feb 13, 2018.

84. Konturek PC, Haziri D, Brzozowski T, Hess T, Heyman S, Kwiecien $\mathrm{S}$, et al. Emerging role of fecal microbiota therapy in the treatment of gastrointestinal and extra-gastrointestinal diseases. J Physiol Pharmacol 2015;66:483-91.

85. Malikowski T, Khanna S, Pardi DS. Fecal microbiota transplantation for gastrointestinal disorders. Curr Opin Gastroenterol 2017;33:8-13.

86. Spindelboeck W, Schulz E, Uhl B, Kashofer K, Aigelsreiter A, ZinkeCerwenka W, et al. Repeated fecal microbiota transplantations attenuate diarrhea and lead to sustained changes in the fecal microbiota in acute, refractory gastrointestinal graft-versus-host-disease. Haematologica 2017;102:e210-e213, [CrossRef]

87. Gupta S, Allen-Vercoe E, Petrof EO. Fecal microbiota transplantation: in perspective. Therap Adv Gastroenterol 2016;9:229-39. [CrossRef]

88. Kelly CR, Ihunnah C, Fischer M, Khoruts A, Surawicz C, Afzali A, et al. Fecal microbiota transplant for treatment of Clostridium difficile infection in immunocompromised patients. Am J Gastroenterol 2014;109:1065-71. [CrossRef]

89. Kakihana K, Fujioka Y, Suda W, Najima Y, Kuwata G, Sasajima S, et al. Fecal microbiota transplantation for patients with steroid-resistant acute graft-versus-host disease of the gut. Blood 2016;128:2083-88.

90. Fischer M, Kao D, Kelly C, Kuchipudi A, Jafri SM, Blumenkehl M, et al. Fecal Microbiota Transplantation is Safe and Efficacious for Recurrent or Refractory Clostridium difficile Infection in Patients with Inflammatory Bowel Disease. Inflamm Bowel Dis 2016;22:2402-9.

91. Teich N, Weber M, Stallmach A. First Occurrence of Severe Extraintestinal Manifestations of Crohn's Disease Following Faecal Microbiota Transplantation. J Crohns Colitis 2016;10:1254-5. [CrossRef]

92. Quera R, Espinoza R, Estay C, Rivera D. Bacteremia as an adverse event of fecal microbiota transplantation in a patient with Crohn's disease and recurrent Clostridium difficile infection. J Crohns Colitis 2014;8:252-3. [CrossRef]

93. De Leon LM, Watson JB, Kelly CR. Transient flare of ulcerative colitis after fecal microbiota transplantation for recurrent Clostridium difficile infection. Clin Gastroenterol Hepatol 2013;11:1036-8. [CrossRef]

94. Satokari R, Mattila E, Kainulainen V, Arkkila PE. Simple faecal preparation and efficacy of frozen inoculum in faecal microbiota transplantation for recurrent Clostridium difficile infection- an observational cohort study. Aliment Pharmacol Ther 2015;41:46-53. [CrossRef]

95. Koenigsknecht MJ, Young VB. Faecal microbiota transplantation for the treatment of recurrent Clostridium difficile infection: current promise and future needs. Curr Opin Gastroenterol 2013;29:628-32.

96. Kelly CR, Kim AM, Laine L, Wu GD. The AGA's Fecal Microbiota Transplantation National Registry: An Important Step Toward Understanding Risks and Benefits of Microbiota Therapeutics. Gastroenterology 2017;152:681-684. [CrossRef] 